\title{
Quantitative Analysis of Tomato Yield and Comprehensive Fruit Quality in Response to Deficit Irrigation at Different Growth Stages
}

\author{
Xuelian Jiang and Yueling Zhao' \\ Key Laboratory of Biochemistry and Molecular Biology in Universities of \\ Shandong, Weifang University, Weifang 261061
}

\author{
Ling Tong \\ Center for Agricultural Water Research in China, China Agricultural \\ University, Beijing 100083, China;
}

Rui Wang ${ }^{1}$ and Sheng Zhao'

Key Laboratory of Biochemistry and Molecular Biology in Universities of Shandong, Weifang University, Weifang 261061

Additional index words. tomato, deficit irrigation, fruit yield, fruit quality, comprehensive quality index

\begin{abstract}
To investigate the quantitative response of tomato yield and fruit quality to deficit irrigation applied at different growth stages, greenhouse experiments were conducted in 2017 and 2018. Three irrigation treatments (full irrigation and twothirds or one-third of full irrigation) were applied to greenhouse-grown tomato plants at flowering and fruit development (stage 2) and at fruit maturation stage (stage 3). Grey relational analysis (GRA), the technique for order preference by similarity to an ideal solution (TOPSIS), and principal components analysis (PCA) were used to calculate the comprehensive fruit quality indexes, and combinatorial evaluation method was determined. The results showed that deficit irrigation significantly reduced evapotranspiration (ET) and tomato yield and that relative yield had a negative linear correlation with relative seasonal water deficit $\left(1-E T_{i} / E T_{c}\right)$. However, deficit irrigation improved fruit quality, especially at stage 2 . Total soluble solids, the total soluble sugar concentration, the sugar-to-acid ratio, and vitamin $\mathrm{C}$ in the tomatoes all increased significantly in plants that were deficit irrigated compared with fully irrigated plants, while organic acids and lycopene decreased in both years. There were linear correlations between fruit quality parameters and $1-E_{i} / E T_{c}$. The comprehensive quality index derived from GRA and PCA is reliable, and the comprehensive quality indexes given by GRA, PCA, and a combination of GRA and PCA showed positive linear correlation with $1-E_{\mathrm{i}} / \mathbf{E T}_{\mathrm{c}}$. The comprehensive quality ranking showed that in both years, $F_{2 / 3} M_{1}$ (two-thirds full irrigation at stage 2) gave a better result and CK (full irrigation) the worst. An appropriate water deficit at the flowering and fruit development stage, which results in a trade-off between acceptable yield and improved fruit quality, is recommended. Our results provide a sound basis for tomato production that has a desirable balance between high yield and high fruit quality.
\end{abstract}

Tomatoes are important in human nutrition because they are a good source of antioxidants, minerals, vitamin $\mathrm{C}(\mathrm{VC})$, and

\footnotetext{
Received for publication 7 May 2018. Accepted for publication 13 May 2018.

We are grateful for research grants from the National Natural Science Foundation of China (51709203), the Natural Science Foundation of Shandong Province (ZR2017BEE079), the Doctoral Fund of Weifang University (2017BS11), and the Science and Technology Development Plan of Weifang (2018GX006).

${ }^{1}$ Corresponding author. E-mail: yuelingzhao@ 163.com.

This is an open access article distributed under the CC BY-NC-ND license (https://creativecommons. org/licenses/by-nc-nd/4.0/).
}

organic acids (Erba et al., 2013; Toor et al., 2006). High tomato consumption reduces the risk of certain diseases (Al-Amri, 2013; Massot et al., 2010; Nguyen and Schwartz, 1999). As tomato production is increasing, consumer demand is gradually changing from increased fruit quantity to better fruit quality (Chen et al., 2013; Wang et al., 2015). Water is an essential factor in tomato growth, yield, and fruit quality (Chen et al., 2014; Sun et al., 2013; Wang et al., 2015). Many studies have shown that deficit irrigation improves tomato fruit quality because it leads to increased amounts of sugar, VC, and betacarotene in the fruit (Chen et al., 2013; Favati et al., 2009; Patanè and Cosentino, 2010; Wang et al., 2015; Yang et al., 2017). However, the improvement in tomato fruit quality gained by deficit irrigation is matched by an undesirable reduction of yield due to smaller fruit size and earlier plant senescence (Chen et al., 2014; Hanson et al., 2006; Topcu et al., 2007; Wang et al., 2015; Zheng et al., 2013). Thus the development of an irrigation management program that offers the best compromise between improved fruit quality and reduced quantity is desirable.

Scholars have attempted to find the correct balance between fruit quality and quantity by conducting open field or greenhouse experiments. Chen et al. (2013) determined that the best compromise between fruit quality and quantity was obtained in an arid region when the irrigation amount was reduced to two-thirds full irrigation (the lower and upper irrigation limits were $75 \%$ and $90 \%$ field capacity) at the fruit maturation stage. Wang et al. (2015) showed that the optimal irrigation amount for balancing fruit comprehensive quality and yield was twothirds of the control amount after the seedling stage. Favati et al. (2009) found that in a typical Mediterranean region, the optimal irrigation strategy for balancing fruit quality with yield was to extend the irrigation interval (irrigation was carried out when the cumulative ET minus effective precipitation was 20 or $40 \mathrm{~mm}$ ) and to reduce the irrigation amount by $50 \%$ for the second part of the tomato crop cycle, starting from the onset of fruit ripening. Reasonable deficit irrigation at different growth stages is beneficial because it increases water use efficiency and improves tomato quality (Chen et al., 2013; Favati et al., 2009; Wang et al., 2015). However, before determining a more precise deficit irrigation strategy, greater knowledge of the relationship among tomato yield, fruit quality, and deficit irrigation at different growth stages is required. Equations relating deficit irrigation to fruit quality and crop yield will help to guide tomato irrigation for the production of high-quality tomatoes. Some studies have formulated a relationship between tomato yield and ET (Chen et al., 2013; Kuscu et al., 2014; Stewart et al., 1977; Zheng et al., 2013). Stewart et al. (1977) and Chen et al. (2014) developed a linear model relating relative yield reduction of tomatoes $\left(1-\mathrm{Y}_{\mathrm{a}} / \mathrm{Y}_{\mathrm{m}}\right)$ to a reduction in relative seasonal ET $\left(1-\mathrm{ET}_{\mathrm{a}} / \mathrm{ET}_{\mathrm{m}}\right)$ which was also used to correlate tomato yield with seasonal ET (Chen et al., 2013; Kuscu et al., 2014; Zheng et al., 2013). Tomato yield has been shown to have both linear and nonlinear relationships with soil water tension thresholds (Marouelli and Silva, 2007), soil water deficit (Patanè and Cosentino, 2010), and seasonal irrigation volume (Favati et al., 2009; Kuscu et al., 2014; Zheng et al., 2013). There are many studies of the relationship between yield and water deficit but few studies that formulate the relationship between fruit quality and water deficit.

Tomato quality is the overall result of interactions among different individual quality parameters (Wang et al., 2011). Deficit irrigation affects individual fruit quality parameters in various ways, which makes it 
difficult to determine the treatment that results in the best overall fruit quality. The comprehensive quality index was devised to consider the contribution of individual quality parameters under different deficit irrigation treatments (Wang et al., 2011). Multiple-attribute decision-making can combine all the quality attributes into a comprehensive quality index to represent fruit quality. Among multiple-attribute decisionmaking techniques, TOPSIS, GRA, and PCA are commonly used to compute a comprehensive quality index. TOPSIS uses the best and worst ideal solutions (Chamodrakas et al., 2009; Wang et al., 2010). The best ideal solution represents the optimal solution, and it is derived from the optimal values of alternative solutions, whereas the worst ideal solution is the worst alternative. The alternatives are ranked by their similarity to the best ideal solution (Chamodrakas et al., 2009; Wang et al., 2010). Wang et al. (2011) used TOPSIS to find a comprehensive quality index for tomatoes under different deficit irrigation applications. GRA is based on grey system theory. It can be used to determine the complicated interrelationships of multiple characteristics, and it is an effective way to analyze processes with many parameters (Tamrin et al., 2014; Wang et al., 2013). PCA reduces many indicators to a few relatively independent principal components by parameter extraction and data reduction, and the source of parameters can be identified after reducing the number of observable parameters at each step (Lan et al., 2014; Lu et al., 2009; Zabalza et al., 2014). Wang et al., (2015) used GRA and PCA to calculated a comprehensive quality index for tomatoes under different deficit irrigation treatments and nitrogen application programs. Their results showed that GRA and PCA both provided suitable indexes. However, the methodology of computing a comprehensive quality index under deficit irrigation at different growth stages needs be further studied.

The quantitative relationship between water deficit and tomato yield has been studied (Chen et al., 2013; Kuscu et al., 2014; Patanè and Cosentino, 2010; Zheng et al., 2013). However, there are few studies (Chen et al., 2013; Patanè and Cosentino, 2010) of the quantitative relationships between water deficit and individual quality attributes (e.g., sugar content, VC content, organic acid content, and the sugar-to-acid ratio), especially between comprehensive quality indexes and water deficit. The quantitative relationship between the comprehensive quality of tomatoes and water deficit at different growth stages can provide a basis for the formulation of an irrigation program for high-quality tomato production. Thus, the objectives of this study are 1) to quantify the effects of deficit irrigation at different growing stages on tomato yield and individual quality parameters; 2) to determine the best method of computing the comprehensive quality index by comparing GRA, TOPSIS, and PCA and identify its response to deficit irrigation; and 3) to determine an optimal tomato irrigation program that balances reduced yield with improved the comprehensive fruit quality.

\section{Materials and Methods}

\section{Experimental site}

The greenhouse experiments were conducted at Weifang University (latitude $36^{\circ} 71^{\prime} \mathrm{N}$, longitude $119^{\circ} 36^{\prime} \mathrm{E}$, altitude $27.03 \mathrm{~m}$ ) from 8 Apr. 2017 to 30 July 2017 and at Gaomi experimental station (latitude $36^{\circ} 38^{\prime} \mathrm{N}$, longitude $119^{\circ} 56^{\prime} \mathrm{E}$, altitude $26.67 \mathrm{~m}$ ) from 27 June 2018 to 13 Oct. 2018 in Weifang City, Shandong Province. Both locations are in the same subhumid climate zone with mean annual precipitation $646 \mathrm{~mm}$, mean annual pan evaporation $1838 \mathrm{~mm}$, mean annual temperature $11.7^{\circ} \mathrm{C}$, mean annual sunshine duration $>2800 \mathrm{~h}$, and mean frost-free days $197 \mathrm{~d}$. A standard automatic weather station (Hobo, Onset Computer Corp., USA) was located at the center of each greenhouse to provide continuous measurement of solar radiation $\left(R_{a}\right)$, air temperature $\left(T_{a}\right)$, wind speed at $2 \mathrm{~m}$ height, and relative humidity $(R H)$ during the experimental period. The meteorological variables for the period are shown in Fig. 1.

The tomato (Solanum lycopersicum L.) varieties were Baoli 3 (2017) and Xingtian 576 (2018). The plants were transplanted into plastic pots $(21 \mathrm{~cm}$ high, top diameter $30 \mathrm{~cm}$, bottom diameter $20 \mathrm{~cm}$ ). Each pot was filled with $6 \mathrm{~kg}$ light sandy loam that had been airdried and sieved with a 5-mm sieve. Soil bulk density and field water capacity were $1.38 \mathrm{~g} /$ $\mathrm{cm}^{3}$ and $0.29 \mathrm{~cm}^{3} / \mathrm{cm}^{3}$ in 2017 and $1.40 \mathrm{~g} / \mathrm{cm}^{3}$ and $0.30 \mathrm{~cm}^{3} / \mathrm{cm}^{3}$ in 2018 .

\section{Experimental design}

Three irrigation treatments (full irrigation, two-thirds, and one-third full irrigation) were applied in both years at flowering and fruit development (stage 2, from first fruit set to first fruit maturity) and at fruit maturation (stage 3, from first fruit maturity to uprooting plants after all fruit have been harvested). Nine treatments were arranged in a randomized complete block design with eight replicates for each treatment. At the seedling stage, all pots were fully irrigated. CK treatment was irrigation to $90 \%$ of field water capacity when the soil water content had decreased to $75 \%$ of field water capacity. Deficit irrigation treatments were administered at the same time as CK. The irrigation amounts for all treatments at different growth stages in both years are shown in Table 1 . Tomato plants of similar height were transplanted on 8 Apr. 2017 and 27 June 2018, with one plant per pot. Each pot was fertilized with $0.6 \mathrm{~g} \mathrm{~N}, 0.6 \mathrm{~g} \mathrm{P}_{2} \mathrm{O}_{5}$, and $0.3 \mathrm{~g} \mathrm{~K}_{2} \mathrm{O}$ as base fertilizer and top-dressed with $0.6 \mathrm{~g} \mathrm{~N}$ and $0.3 \mathrm{~g} \mathrm{~K}_{2} \mathrm{O}$ on 10 June 2017 and 10 Aug. 2018.

Measurements. ET, yield, and water use efficiency. ET (in liters) is calculated from soil water balance using the following equation according to Qiu et al. (2017a, 2017b, 2018):

$$
E T=\left(W_{n}-W_{n+1}\right) / \rho+(I-D)
$$

where $W_{n}$ and $W_{n+1}$ are the weights of the pots at the end of days $n$ and $n+1(\mathrm{~g}) ; \rho$ is the water bulk density $(1000 \mathrm{~g} / \mathrm{L})$; and $I$ and $D$ are irrigation and drainage amounts (in liters).

The pots were weighed daily on an electronic scale with $1 \mathrm{~g}$ precision at 18:00 $\mathrm{h}$. After each irrigation event, $D$ for each pot was measured from the drainage water collected in a glass bottle placed underneath the pot.

Each fruit was weighed as it was harvested. Mean fruit weight and total yield for each treatment were calculated.

Fruit quality parameters. Several individual fruit quality parameters, the fruit shape
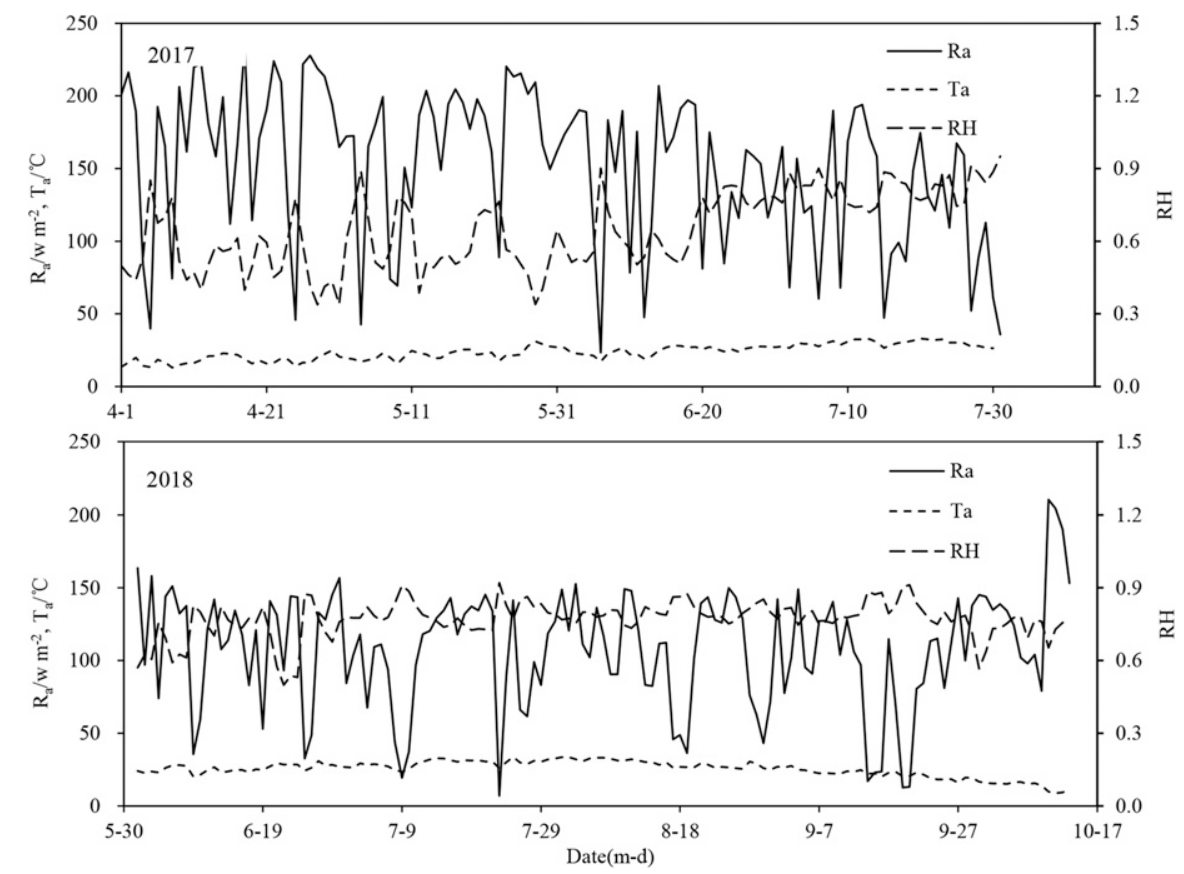

Fig. 1. Daily mean solar radiation $\left(R_{a}\right)$, daily mean air temperature $\left(T_{a}\right)$, and daily mean air relative humidity (RH) at different growth stages in the greenhouse in 2017 and 2018. 


\begin{tabular}{|c|c|c|c|c|c|c|}
\hline \multirow[b]{2}{*}{ Crop season } & \multirow[b]{2}{*}{ Treatment } & \multirow[b]{2}{*}{ Description } & \multicolumn{4}{|c|}{ Irrigation amount } \\
\hline & & & Stage 1 & Stage 2 & Stage 3 & Whole season \\
\hline \multirow[t]{12}{*}{2017} & $\mathrm{~F}_{1 / 3} \mathrm{M}_{1}$ & $1 / 3$ full irrigation at stage 2 & 0.95 & 1.80 & 3.78 & 6.53 \\
\hline & $\mathrm{F}_{2 / 3} \mathrm{M}_{1}$ & $2 / 3$ full irrigation at stage 2 & 0.90 & 3.60 & 3.78 & 8.28 \\
\hline & $\mathrm{F}_{1} \mathrm{M}_{2 / 3}$ & $2 / 3$ full irrigation at stage 3 & 0.92 & 5.40 & 2.52 & 8.84 \\
\hline & $\mathrm{F}_{1} \mathrm{M}_{1 / 3}$ & $1 / 3$ full irrigation at stage 3 & 0.93 & 5.40 & 1.26 & 7.59 \\
\hline & $\mathrm{F}_{2 / 3} \mathrm{M}_{2 / 3}$ & $2 / 3$ full irrigation at stages 2 and 3 & 0.93 & 3.60 & 2.52 & 7.05 \\
\hline & $\mathrm{F}_{2 / 3} \mathrm{M}_{1 / 3}$ & $2 / 3$ full irrigation at stage 2 and $1 / 3$ full irrigation at stage 3 & 0.92 & 3.60 & 1.26 & 5.78 \\
\hline & $\mathrm{F}_{1 / 3} \mathrm{M}_{2 / 3}$ & $1 / 3$ full irrigation at stage 2 and $2 / 3$ full irrigation at stage 3 & 0.91 & 1.80 & 2.52 & 5.23 \\
\hline & $\mathrm{F}_{1 / 3} \mathrm{M}_{1 / 3}$ & $1 / 3$ full irrigation at stages 2 and 3 & 0.89 & 1.80 & 1.26 & 3.95 \\
\hline & $\mathrm{CK}$ & Full irrigation & 0.90 & 5.40 & 3.78 & 10.08 \\
\hline & Stage 1 & Seedling stage (8-25 Apr.) & - & - & - & - \\
\hline & Stage 2 & Flowering and fruit development stage (26 Apr.-25 June) & - & - & - & - \\
\hline & Stage 3 & Fruit maturation stage (26 June-30 July) & - & - & - & - \\
\hline \multirow[t]{12}{*}{2018} & $\mathrm{~F}_{1 / 3} \mathrm{M}_{1}$ & $1 / 3$ full irrigation at stage 2 & 1.40 & 2.08 & 2.70 & 6.18 \\
\hline & $\mathrm{F}_{2 / 3} \mathrm{M}_{1}$ & $2 / 3$ full irrigation at stage 2 & 1.40 & 4.05 & 2.70 & 8.15 \\
\hline & $\mathrm{F}_{1} \mathrm{M}_{2 / 3}$ & $2 / 3$ full irrigation at stage 3 & 1.40 & 5.82 & 1.80 & 9.02 \\
\hline & $\mathrm{F}_{1} \mathrm{M}_{1 / 3}$ & $1 / 3$ full irrigation at stage 3 & 1.40 & 5.82 & 0.90 & 8.12 \\
\hline & $\mathrm{F}_{2 / 3} \mathrm{M}_{2 / 3}$ & $2 / 3$ full irrigation at stages 2 and 3 & 1.40 & 4.05 & 1.80 & 7.25 \\
\hline & $\mathrm{F}_{2 / 3} \mathrm{M}_{1 / 3}$ & $2 / 3$ full irrigation at stage 2 and $1 / 3$ full irrigation at stage 3 & 1.40 & 4.05 & 0.90 & 6.35 \\
\hline & $\mathrm{F}_{1 / 3} \mathrm{M}_{2 / 3}$ & $1 / 3$ full irrigation at stage 2 and $2 / 3$ full irrigation at stage 3 & 1.40 & 2.08 & 1.80 & 5.28 \\
\hline & $\mathrm{F}_{1 / 3} \mathrm{M}_{1 / 3}$ & $1 / 3$ full irrigation at stages 2 and 3 & 1.40 & 2.08 & 0.90 & 4.38 \\
\hline & $\mathrm{CK}$ & Full irrigation & 1.40 & 5.82 & 2.70 & 9.92 \\
\hline & Stage 1 & Seedling stage (27 June-8 July) & - & - & - & - \\
\hline & Stage 2 & Flowering and fruit development stage (9 July-27 Aug.) & - & - & - & - \\
\hline & Stage 3 & Fruit maturation stage (28 Aug. -13 Oct.) & - & - & - & - \\
\hline
\end{tabular}

Stage 1 is the seedling stage (from transplant to first fruit set), stage 2 is the flowering and fruit development stage (from first fruit set to first fruit maturity), stage 3 is the fruit maturation stage (from first fruit maturity to uprooting crops after all fruit is harvested). CK $=$ full irrigation.

index (SI), organic acid content (OA), total soluble solids content (TSS), total soluble sugar concentration (TSSC), VC, and lycopene content (LYC), were measured during the fruit maturation and harvesting stage. OA was titrated with $0.1 \mathrm{~mol} / \mathrm{L} \mathrm{NaOH}$ according to Association of Official Analytical Chemists (1990). TSS was measured by a handheld refractometer (ATAGO, PAL-1, Co., Ltd., Tokyo, Japan). TSSC was observed using the anthrone-sulphuric acid colorimetric method described by Leyva et al. (2008). VC was measured using the 2,6-dichloroindophenol titrimetric method (Association of Official Analytical Chemists, 1984). LYC was measured by the spectrophotometric method developed by Davies (1976) and Sharma and Le Maguer (1996). The sugar to acid content ratio (SAR) was defined as the ratio of TSSC to OA. The vertical and horizontal diameters of the fruit were measured by a Vernier caliper, and SI was defined as the ratio of vertical diameter to horizontal diameter (Chen et al., 2013).

Computation of the comprehensive fruit quality index. GRA, which is based on the grey system, considers all the treatments in the experiment. Each treatment is defined as one of a factor in the system. The comprehensive fruit quality index is calculated by the following steps (Jing and Hong, 2012; Xiao et al., 2012; Xie and Mao, 2012).

(1) Normalize the fruit quality parameters. The ideal treatment $\left(x_{0 j}\right)$, which consists of the $n$ maximums of the individual fruit quality parameters, is determined; other treatments in the experiment are defined as $x_{i j}$. The $x_{i j}$ are normalized by:

$$
y_{i j}=\frac{x_{i j}}{x_{0 j}}, i=1,2 \ldots, m ; j=1,2 \ldots, n
$$

where $y_{i j}$ is the normalized value of a fruit quality parameter and varies between 0 and 1 ; $m$ is the number of experimental treatments; and $n$ is the number of fruit quality parameters. In this study, $m=9$ and $n=8$.

(2) Determine the grey relational coefficient. The grey relational coefficient $\left(\xi_{i j}\right)$ is calculated according to Lu et al., (2009):

$$
\xi_{i j}=\frac{\min _{i} \min _{j}\left|y_{i}^{0}-y_{i j}\right|+\zeta \max _{i} \max _{j}\left|y_{i}^{0}-y_{i j}\right|}{\left|y_{i}^{0}-y_{i j}\right|+\zeta \max _{i} \max _{j}\left|y_{i}^{0}-y_{i j}\right|}
$$

where $y_{i}^{0}$ is the ideal normalized value of the $i$ th fruit quality parameter, which is the greatest normalized value and is set to be 1.0 and $\zeta$ is the distinguishing coefficient, which is defined as 0.5 according to Wang et al. (2015).

(3) Estimate the comprehensive fruit quality index for different irrigation treatments. The grey relational $\operatorname{rank}\left(Q_{R i}^{*}\right)$ is the comprehensive fruit quality index and is calculated by the weighted sum of $\xi_{i j}$ :

$$
Q_{R i}^{*}=\sum_{i=1}^{n} w_{j} \xi_{i j}
$$

where $w_{j}$ is the weighting factor of the $j$ th fruit quality parameter, which is determined according to Wang et al. (2011).

Technique for order preference by similarity to an ideal solution. TOPSIS, which is based on the best and worst ideal solutions, quantifies the comprehensive quality index (Deng et al., 2000), which is calculated in the following steps.

(1) Normalize the fruit quality parameters. The normalized value of the fruit quality parameters $\left(p_{i j}\right)$ is calculated by:

$$
p_{i j}=x_{i j} / \sum_{i=1}^{m} x_{i j}, i=1,2 \ldots m, j=1,2 \ldots n
$$

(2) Calculate the best $\left(A^{+}\right)$and worst $\left(A^{-}\right)$ ideal solutions. The solutions $A^{+}$and $A^{-}$are calculated from the normalized fruit quality parameter values using Eqs. [6] and [7]:

$$
\begin{aligned}
A_{j}^{+}= & \left\{p_{1}^{+}, p_{2}^{+}, \ldots p_{j}^{+} \ldots p_{n}^{+}\right\} \\
= & \left\{\left(\max _{i} p_{i j} \mid j \in J_{1}\right),\left(\min _{i} p_{i j} \mid j \in J_{2}\right)\right. \\
& \mid i=1,2 \ldots m\}
\end{aligned}
$$

$$
\begin{aligned}
A_{j}^{-}= & \left\{p_{1}^{-}, p_{2}^{-}, \ldots p_{j}^{-} \ldots p_{n}^{-}\right\} \\
= & \left\{\left(\min _{i} p_{i j} \mid j \in J_{1}\right),\left(\max _{i} p_{i j} \mid j \in J_{2}\right)\right. \\
& \| i=1,2 \ldots m\}
\end{aligned}
$$

where $J_{1}$ is the set of the-greater-the-betterthe quality parameters and $J_{2}$ is the set of thesmaller-the-better-the quality parameters.

(3) Determine the weighted Euclidean distances. The weighted Euclidean distance between $A_{i}$ and $A^{+}\left(L_{i}^{+}\right)$is given by

$$
L_{i}^{+}=\sqrt{\sum_{j=1}^{n} w_{j}\left(r_{i j}-r_{j}^{+}\right)^{2}}, i=1,2 \ldots m
$$

Similarly, the weighted Euclidean distance between $A_{i}$ and $A^{-}\left(L_{i}^{-}\right)$is given by

$$
L_{i}^{-}=\sqrt{\sum_{j=1}^{n} w_{j}\left(r_{i j}-r_{j}^{-}\right)^{2}}, i=1,2 \ldots m
$$

(4) Calculate the comprehensive fruit quality index for different treatments. The comprehensive fruit quality index $\left(Q_{T i}^{*}\right)$ is 
given by the closeness of the quality vector of every treatment to the positive ideal solution, and it is calculated by

$$
Q_{T i}^{*}=\frac{L_{i}^{-}}{L_{i}^{+}+L_{i}^{-}}
$$

Principal component analysis. PCA is used to reduce the number of observational parameters at each treatment. The comprehensive fruit quality index of tomatoes is computed in the following steps (Fung and Kang, 2005; Lu et al., 2009).

(1) Establish the original data matrix $x_{i j}$ of fruit quality parameters.

$$
x_{m \times n}=\left(\begin{array}{cccc}
x_{11} & x_{12} & \ldots & x_{1 n} \\
x_{21} & x_{22} & \ldots & x_{2 n} \\
\ldots & \ldots & \ldots & \ldots \\
x_{m 1} & x_{m 2} & \ldots & x_{m n}
\end{array}\right)
$$

where $m$ is the number of experimental treatments, and $n$ is the number of fruit quality parameters. In this study, $m=9$ and $n=8$.

(2) Normalize the fruit quality parameters. To ensure consistency in the directionality of fruit quality parameters, negative optimal parameters were converted into positive optimal parameters by

$$
x_{i j}^{\prime}=-x_{i j}
$$

where the $x_{i j}^{\prime}$ are the positive optimal fruit quality parameters. The $x_{i j}^{\prime}$ are normalized by

$$
Z_{i j}=\frac{x_{i j}^{\prime}-\overline{x_{j}^{\prime}}}{\sigma}
$$

where the $Z_{i j}$ are the normalized parameters: $\sigma=\sqrt{\frac{1}{m-1} \sum_{i=1}^{m}\left(x_{i j}^{\prime}-\overline{x_{j}^{\prime}}\right)^{2}}$ and $\overline{x_{j}^{\prime}}=\frac{1}{m} \sum_{i=1}^{m} x_{i j}^{\prime}$.

(3) Calculate the correlation coefficient matrix of $Z_{i j}$.

$$
R_{n \times n}=\left(\begin{array}{cccc}
r_{11} & r_{12} & \ldots & r_{1 n} \\
r_{21} & r_{22} & \ldots & r_{2 n} \\
\ldots & \ldots & \ldots & \ldots \\
r_{n 1} & r_{n 2} & \ldots & r_{n n}
\end{array}\right)
$$

where $r_{j k}$ is the Pearson correlation coefficient between $Z_{j}^{\prime}$ and $Z_{k}^{\prime}(k=1,2, \ldots, n)$.

(4) Determine the eigenvalues and eigenvectors. The eigenvalues and eigenvectors of $R_{n \times n}$ are calculated by

$$
\left(R_{n \times n}-\lambda_{p} I\right) \alpha_{p i}=0
$$

where $\lambda_{p}$ are the eigenvalues, $\sum_{p=1}^{n} \lambda_{p}=n$, In this study, $P=2$, and $\alpha_{p i}$ are the eigenvectors corresponding to the $\lambda_{p}$, defined as $\left(\alpha_{p 1}, \alpha_{p 2}, \ldots, \alpha_{p n}\right)^{T}$.

(5) Calculate the principal components corresponding to the $\lambda_{p}$. The variance contribution rate corresponding to the $p$ th principal component $\left(\eta_{p}\right)$ is determined by

$$
\eta_{p}=\frac{\lambda_{p}}{n}, p=1,2 \cdots n .
$$

The pth principal component $\left(f_{i p}\right)$ of each irrigation treatment is calculated by:

$$
f_{i p}=\alpha_{p 1} Z_{i 1}+\alpha_{p 2} Z_{i 2}+\ldots+\alpha_{p n} Z_{i n}
$$
index of each irrigation treatment. The
(6) Evaluate the comprehensive quality

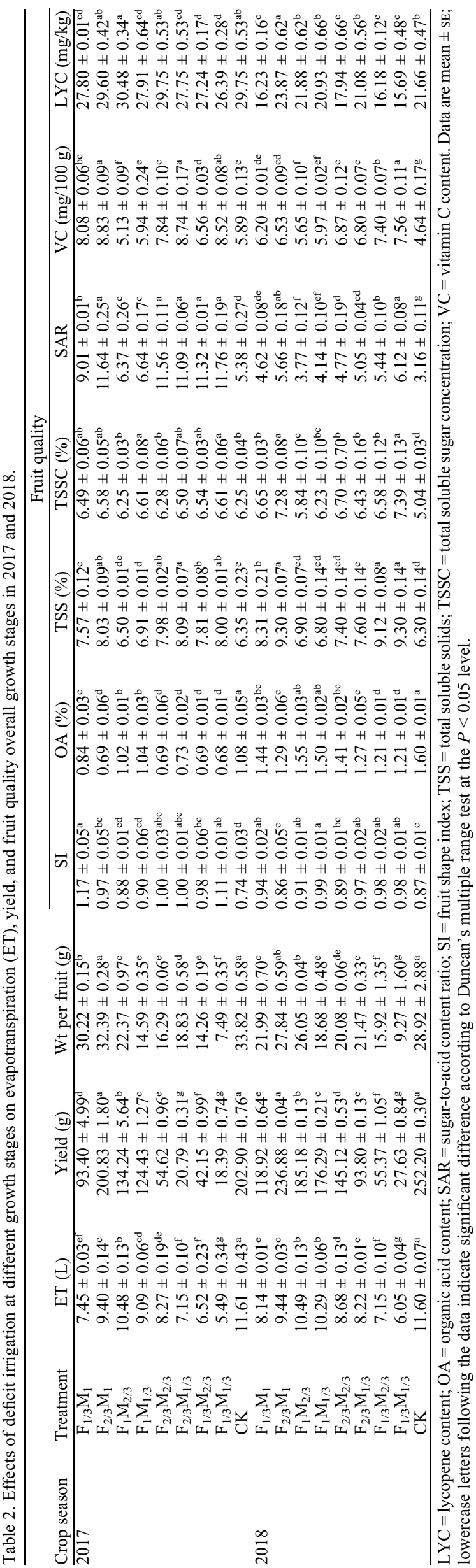


maximum $\left(d_{i}^{+}\right)$and minimum $\left(d_{i}^{-}\right)$principal components are calculated by

$$
\begin{aligned}
& d_{i}^{+}=\sqrt{\sum_{j=1}^{p} w_{j}\left(f_{i j}-f_{j}^{+}\right)^{2}}, i=1,2, \ldots, m \\
& d_{i}^{-}=\sqrt{\sum_{j=1}^{p} w_{j}\left(f_{i j}-f_{j}^{-}\right)^{2}}, i=1,2, \ldots, m
\end{aligned}
$$

where $w_{j}$ is the variance contribution rate corresponding to the $j$ th principal component and $f_{j}^{+}$and $f_{j}^{-}$are the maximum and minimum values of the $j$ th principal component under different treatments.

The comprehensive quality index of each treatment $\left(Q_{P i}^{*}\right)$ is determined by:

$$
Q_{P i}^{*}=\frac{d_{i}^{-}}{d_{i}^{+}+d_{i}^{-}}
$$

Combined computation. The combined comprehensive fruit quality index is derived from the comprehensive fruit quality indexes given by the different methods to ensure that the final result is truly representative. The steps in the computation of the combined comprehensive fruit quality index are as follows.

(1) Establish the data matrix $X$ for the evaluation.

$$
X_{M \times N}=\left(\begin{array}{cccc}
X_{11} & X_{12} & \ldots & X_{1 N} \\
X_{21} & X_{22} & \ldots & X_{2 N} \\
\ldots & \ldots & \ldots & \ldots \\
X_{M 1} & X_{M 2} & \ldots & X_{M N}
\end{array}\right)
$$

where $X_{i j}$ is the comprehensive fruit quality index of the $i$ th treatment calculated by the $j$ th computation method $(i=1,2, \ldots, M ; j=1$, $2, \ldots, N)$. In this study, $M=9$ and $N=2$.

(2) Normalize the data matrix. The computed comprehensive quality indexes have the same order of magnitude, so normalization of the data matrix is not required.

(3) Spearman's rank correlation analysis. Spearman rank correlation between the ranked comprehensive quality indexes that were computed by the different methods and the individual quality parameters is calculated.

(4) Calculate the weights of the different calculation methods. The weight of the $j$ th estimated method $\left(w_{x}\right)$ is calculated as

$$
w_{j}=\frac{\rho_{j}}{\sum_{N}^{i=1} \rho_{i}}, i=1,2 \ldots, N ; j=1,2 \ldots, N
$$

where $\rho_{j}$ is the sum of the Spearman correlation coefficients between the comprehensive quality index ranks calculated by the $j$ th method and the individual quality parameters.

(5) Determine the combined comprehensive fruit quality index. The combined comprehensive fruit quality index $\left(Q_{c i}{ }^{*}\right)$ was calculated by

$$
Q_{c i}^{*}=\sum_{j=1}^{N} w_{j} X_{i j}
$$

(6) Examine the result of the combined computation. The Pearson correlation coefficients between the ranked comprehensive quality indexes given by the combined computation and the original computation $\left(\rho_{a j}\right)$ are calculated, and the average correlation coefficient $\left(\rho_{a}\right)$ is calculated by

$$
\rho_{a}=\frac{1}{N} \sum_{j=1}^{N} \rho_{a j}
$$

A higher average correlation coefficient represents better correspondence between the
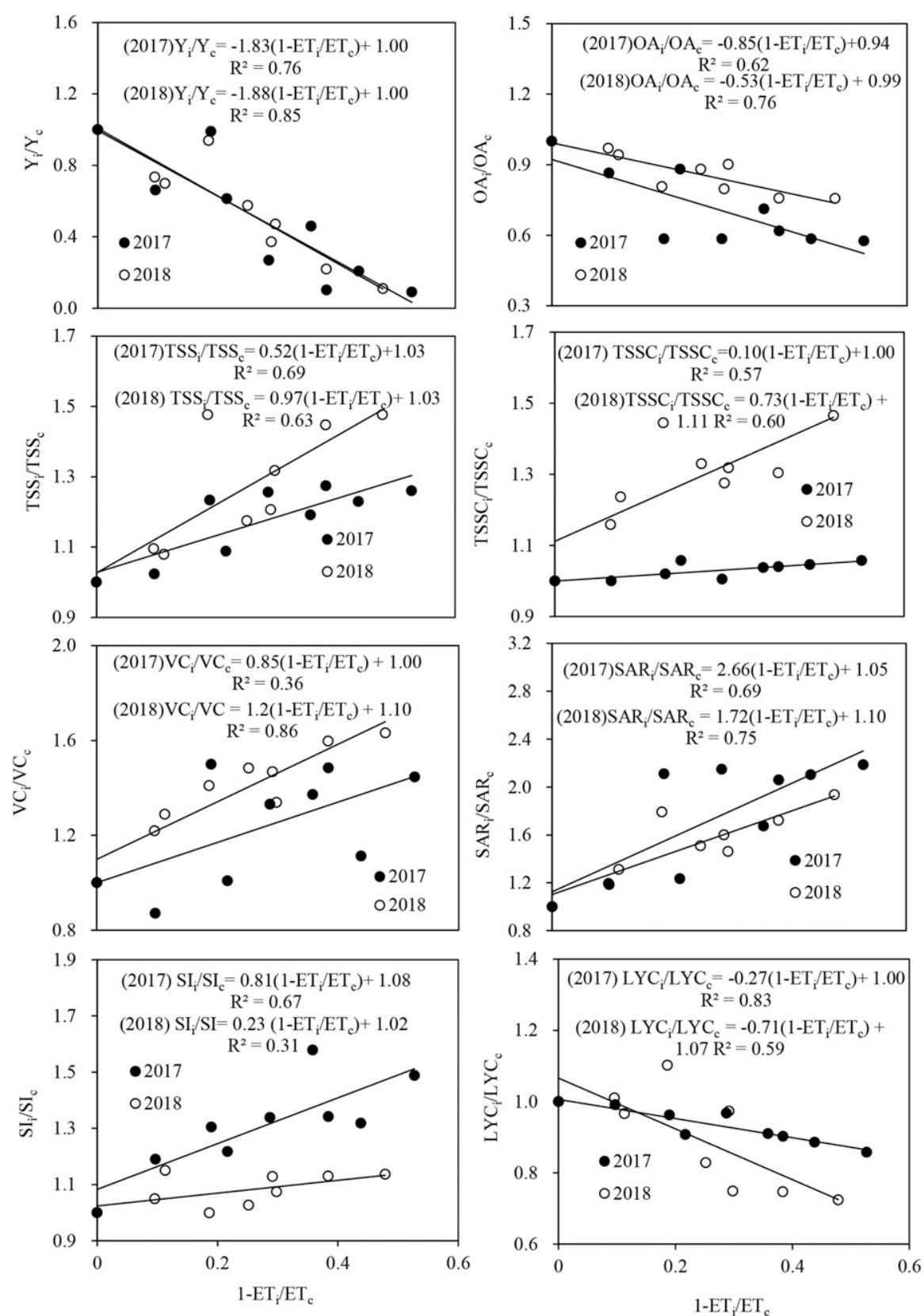

Fig. 2. Relationships between relative yield $\left(\mathrm{Y}_{\mathrm{i}} / \mathrm{Y}_{\mathrm{c}}\right)$, individual fruit quality parameters $\left(\mathrm{OA}_{\mathrm{i}} / \mathrm{OA}_{\mathrm{c}}\right.$, $\mathrm{TSS}_{\mathrm{i}} / \mathrm{TSS}_{\mathrm{c}}, \mathrm{TSSC}_{\mathrm{i}} / \mathrm{TSSC}_{\mathrm{c}}, \mathrm{VC}_{\mathrm{i}} / \mathrm{VC}_{\mathrm{c}}, \mathrm{SAR}_{\mathrm{i}} / \mathrm{SAR}_{\mathrm{c}}, \mathrm{SI}_{\mathrm{i}} / \mathrm{SI}_{\mathrm{c}}$, and $\mathrm{LYC}_{\mathrm{i}} / \mathrm{LCY}_{\mathrm{c}}$ ) and relative seasonal water deficit $\left(1-\mathrm{ET}_{\mathrm{i}} / \mathrm{ET}_{\mathrm{c}}\right)$ in 2017 and 2018. putation (Wang et al., 2015).

Data analysis. The statistical analysis, matrix calculation and Spearman's correlation analysis were performed using SPSS 17.0 (SPSS Inc., Armonk, NY). The mean tiple range test at the $P_{0.05}$ level.

\section{Results and Discussion}

Effect of deficit irrigation on ET and yield. Deficit irrigation significantly reduces ET compared with CK (Table 2). For the $2 / 3$ full irrigation at stages $2(\mathrm{~F})$ and $3(\mathrm{M})\left(\mathrm{F}_{2 / 3} \mathrm{M}_{2 / 3}\right)$ and $\mathrm{F}_{1 / 3} \mathrm{M}_{1 / 3}$, ET was reduced by about $29 \%$ and $53 \%$ in 2017 and $25 \%$ and $48 \%$ in 2018 combined computation and the original com-

HortScience Vol. 54(8) August 2019 
respectively. Many studies have also shown that increased water deficit reduces ET (Chen et al., 2013; Topcu et al., 2007; Wang et al., 2015). The effect of water deficit on ET for stage 2 and stage 3 was evident. Compared with CK, ET decreased by $\approx 19 \%$ and $36 \%$ in 2017 and $19 \%$ and $30 \%$ in 2018 for $\mathrm{F}_{2 / 3} \mathrm{M}_{1}$ and $\mathrm{F}_{1 / 3} \mathrm{M}_{1}$, and ET decreased by $\approx 10 \%$ and $22 \%$ in 2017 and $10 \%$ and $11 \%$ in 2018 for $F_{1}$ $\mathrm{M}_{2 / 3}$ and $\mathrm{F}_{1} \mathrm{M}_{1 / 3}$. Chen et al. (2013) also found that water deficit at stage 2 and stage 3 significantly reduced ET.

Tomato yield decreased significantly with the reduction of the irrigation amount, except for $F_{2 / 3} M_{1}$ (Table 2). The yield for $F_{2 / 3} M_{2 / 3}$ and $\mathrm{F}_{1 / 3} \mathrm{M}_{1 / 3}$ decreased by about $73 \%$ and $90 \%$ in 2017 and $42 \%$ and $89 \%$ in 2018 compared with CK. These results are similar to previous findings (Chen et al., 2013; Jensen et al., 2010; Topcu et al., 2007; Wang et al., 2015). This is mainly because severe water stress resulted in smaller fruit size and earlier plant senescence. (Hanson et al., 2006; Topcu et al., 2007; Zheng et al., 2013). No significant yield reduction was found for $\mathrm{F}_{2 / 3}$ $\mathrm{M}_{1}$, probably because the decrease to twothirds of the full irrigation amount at stage 2 was not a large enough deficit to affect yield, this finding is consistent with the results of Chen et al. (2014). However, increased water deficit significantly reduced the yield. The yield for $\mathrm{F}_{1 / 3} \mathrm{M}_{1}$ decreased by $\approx 53 \%$ to $54 \%$ compared with $\mathrm{CK}$. The water deficit at stage 3 has a significant effect on the yield. Reduction of yield under water deficit is mainly due to decreased weight per fruit (Table 2). Some studies have also shown that water deficit at any growth stage does not decrease fruit numbers per plant but significantly decreases weight per fruit (Chen et al., 2013; Mitchell et al., 1991).

Effect of deficit irrigation on fruit quality. Positive effects of deficit irrigation on fruit quality were found in our study. TSS, SAR, and TSSC increased significantly compared with $\mathrm{CK}$, and OA decreased significantly with the decrease in the irrigation amount in both years (Table 2). Fruit taste is mainly determined by TSSC, OA, and SAR (Dorais et al., 2001; Kader, 2008). The results indicate that within a certain range, water deficit improved fruit taste because it increased TSS and SAR and reduced OA. This was mainly because increased water stress reduced water uptake by the tomato fruit but increased the concentration of solute in sap, which increased the concentration of various components (e.g., sugars) in the fruits and thus had positive effect on overall taste (Mitchell et al., 1991).

VC content increased with the reduction in irrigation amount, and the highest values were found in treatment $\mathrm{F}_{2 / 3} \mathrm{M}_{1}$ and $\mathrm{F}_{1 / 3} \mathrm{M}_{1 / 3}$ $(8.83 \mathrm{mg} / 100 \mathrm{~g}$ in 2017 and $7.56 \mathrm{mg} / 100 \mathrm{~g}$ in 2018). Similar results were also found by Chen et al. (2013) and Wang et al. (2015). This result is due to the higher sugar content when there is water stress, which promotes VC synthesis during fruit ripening (VeitKöhler et al., 1999). Water deficit at stage 2 produced significantly higher $\mathrm{VC}$ than water deficit at stage 3 in both years (Table 2). The main reason for this is that water deficit at stage 2 reduces leaf area index and thus increases fruit exposure to light (Wang et al., 2011), and the additional light increases VC synthesis (Dumas et al., 2003). Lycopene content was significantly reduced for all deficit irrigation treatments compared with $\mathrm{CK}$, except that there was no significant difference for $\mathrm{F}_{2 / 3} \mathrm{M}_{1}$. No significant difference were found in SI in water deficit treatments, but SI in water deficit treatments was significantly higher than that in $\mathrm{CK}$ (Table 2).

Relationship between yield, fruit quality, and deficit irrigation. Figure 2 shows the relationships between relative yield $\left(\mathrm{Y}_{\mathrm{i}} / \mathrm{Y}_{\mathrm{c}}\right)$, relative fruit quality parameters $\left(\mathrm{OA}_{\mathrm{i}} / \mathrm{OA}_{\mathrm{c}}\right.$, $\mathrm{TSS}_{\mathrm{i}} / \mathrm{TSS}_{\mathrm{c}}, \mathrm{TSSC}_{\mathrm{i}} / \mathrm{TSSC}_{\mathrm{c}}, \mathrm{VC}_{\mathrm{i}} / \mathrm{VC}_{\mathrm{c}}, \mathrm{SAR}_{\mathrm{i}}$
$/ \mathrm{SAR}_{\mathrm{c}}, \mathrm{SI}_{\mathrm{i}} / \mathrm{SI}_{\mathrm{c}}$, and $\left.\mathrm{LYC}_{\mathrm{i}} / \mathrm{LCY}_{\mathrm{c}}\right)$ and relative seasonal water deficit $\left(1-E T_{i} / E T_{c}\right) . \quad Y_{i} / Y_{c}$ decreased linearly as $1-\mathrm{ET}_{\mathrm{i}} / \mathrm{ET}_{\mathrm{c}}$ increased in both years, with a high determination coefficient $\left(R^{2}\right)$ (Fig. 2). Patanè et al. (2011) found an exponential relationship between tomato yield and seasonal ET, but we found a linear relationship between relative yield and seasonal ET. Chen et al. $(2013,2014)$ found a positive linear correlation between relative yield and relative seasonal ET, and a negative linear correlation between relative yield and $1-\mathrm{ET}_{\mathrm{i}} / \mathrm{ET}_{\mathrm{c}}$ for tomatoes. Similar results were found by Karam et al. (2007) for sunflowers and by Sezen et al. (2008) for green beans.

$\mathrm{TSS}_{\mathrm{i}} / \mathrm{TSS}_{\mathrm{c}}, \quad \mathrm{TSSC}_{\mathrm{i}} / \mathrm{TSSC}_{\mathrm{c}}, \mathrm{SAR}_{\mathrm{i}} / \mathrm{SAR}_{\mathrm{c}}$ $\mathrm{VC}_{\mathrm{i}} / \mathrm{VC}_{\mathrm{c}}$, and $\mathrm{SI}_{\mathrm{i}} / \mathrm{SI}_{\mathrm{c}}$ showed significant positive linear correlations with $1-\mathrm{ET}_{\mathrm{i}} / \mathrm{ET}_{\mathrm{c}}$ as shown in Fig. 2. $\mathrm{OA}_{\mathrm{i}} / \mathrm{OA}_{\mathrm{c}}$ and $\mathrm{LYC}_{\mathrm{i}} / \mathrm{LCY}_{\mathrm{c}}$ each showed significant negative linear correlation with $1-\mathrm{ET}_{\mathrm{i}} / \mathrm{ET}_{\mathrm{c}}$. Similar results have been found in other studies. Chen et al. (2013, 2014) showed that a linear model best fitted the correlations between relative TSS, relative $\mathrm{SAR}$, relative $\mathrm{OA}$, and relative $\mathrm{VC}$ and $1-\mathrm{ET}_{\mathrm{i}} / \mathrm{ET}_{\mathrm{c}}$ or relative seasonal ET. The gradients of the fitted curves show the sensitivity of fruit quality to seasonal ET, and the higher absolute values show an increased sensitivity to water deficit (Chen et al., 2013). We found strong linear relationships among TSS, TSSC, SAR, VC, OA, LYC, SI, and ET, and SAR,VC, OA and TSS showed high the sensitivity to water deficit, according to the absolute values of the gradients.

Determination of comprehensive quality index and its response to deficit irrigation. Comprehensive quality indexes of the tomatoes were determined by GRA (Table 3), TOPSIS (Table 4), and PCA (Table 5). Ranking the GRA scores showed that $\mathrm{F}_{2 / 3} \mathrm{M}_{1}$ and $\mathrm{F}_{1 / 3} \mathrm{M}_{1 / 3}$ had higher comprehensive quality index values and that $\mathrm{CK}, \mathrm{F}_{1} \mathrm{M}_{2 / 3}$, and $\mathrm{F}_{1} \mathrm{M}_{1 / 3}$ had lower values in both years (Table 3 ). TOPSIS had different results in 2 years and

Table 3. The grey relational coefficient $\left(\xi_{i j}\right)$, comprehensive fruit quality indexes and its rankings for deficit irrigation at different growth stages using GRA in 2017 and 2018

\begin{tabular}{|c|c|c|c|c|c|c|c|c|c|c|c|}
\hline Crop season & Treatment & $\xi_{i 1}$ & $\overline{\xi_{i 2}}$ & $\overline{\xi_{i 3}}$ & $\overline{\xi_{i 4}}$ & $\overline{\xi_{i 5}}$ & $\xi_{i 6}$ & $\overline{\xi_{i 7}}$ & $\overline{\xi_{i 8}}$ & $\overline{\mathrm{QRi}^{*}}$ & Rank \\
\hline \multirow[t]{10}{*}{2017} & $\mathrm{~F}_{1 / 3} \mathrm{M}_{1}$ & 0.54 & 0.84 & 0.79 & 0.92 & 0.59 & 0.79 & 0.83 & 0.76 & 0.76 & 5 \\
\hline & $\mathrm{F}_{2 / 3} \mathrm{M}_{1}$ & 0.45 & 0.98 & 0.98 & 0.95 & 0.96 & 0.90 & 0.73 & 0.89 & 0.88 & 1 \\
\hline & $\mathrm{F}_{1} \mathrm{M}_{2 / 3}$ & 0.70 & 0.64 & 0.45 & 0.84 & 0.43 & 0.97 & 0.57 & 0.50 & 0.63 & 8 \\
\hline & $\mathrm{F}_{1} \mathrm{M}_{1 / 3}$ & 0.72 & 0.70 & 0.51 & 0.96 & 0.44 & 0.79 & 0.58 & 0.38 & 0.62 & 9 \\
\hline & $\mathrm{F}_{2 / 3} \mathrm{M}_{2 / 3}$ & 0.45 & 0.96 & 0.74 & 0.85 & 0.94 & 0.91 & 0.67 & 0.40 & 0.76 & 4 \\
\hline & $\mathrm{F}_{2 / 3} \mathrm{M}_{1 / 3}$ & 0.47 & 1.00 & 0.95 & 0.92 & 0.85 & 0.78 & 0.67 & 0.44 & 0.78 & 3 \\
\hline & $\mathrm{F}_{1 / 3} \mathrm{M}_{2 / 3}$ & 0.45 & 0.91 & 0.57 & 0.94 & 0.89 & 0.75 & 0.65 & 0.37 & 0.70 & 6 \\
\hline & $\mathrm{F}_{1 / 3} \mathrm{M}_{1 / 3}$ & 0.44 & 0.97 & 0.89 & 0.96 & 0.99 & 0.71 & 0.77 & 0.33 & 0.78 & 2 \\
\hline & $\mathrm{CK}$ & 0.78 & 0.62 & 0.51 & 0.84 & 0.39 & 0.91 & 0.62 & 0.89 & 0.68 & 7 \\
\hline & $w_{j}$ & 0.07 & 0.11 & 0.15 & 0.10 & 0.15 & 0.16 & 0.14 & 0.12 & & \\
\hline \multirow[t]{10}{*}{2018} & $\mathrm{~F}_{1 / 3} \mathrm{M}_{1}$ & 0.69 & 0.74 & 0.78 & 0.77 & 0.57 & 0.51 & 0.69 & 0.58 & 0.66 & 5 \\
\hline & $\mathrm{F}_{2 / 3} \mathrm{M}_{1}$ & 0.58 & 0.97 & 0.94 & 0.96 & 0.80 & 1.00 & 0.61 & 0.89 & 0.86 & 1 \\
\hline & $\mathrm{F}_{1} \mathrm{M}_{2 / 3}$ & 0.79 & 0.56 & 0.67 & 0.62 & 0.46 & 0.80 & 0.66 & 0.77 & 0.66 & 4 \\
\hline & $\mathrm{F}_{1} \mathrm{M}_{1 / 3}$ & 0.75 & 0.55 & 0.64 & 0.68 & 0.51 & 0.73 & 0.78 & 0.49 & 0.64 & 8 \\
\hline & $\mathrm{F}_{2 / 3} \mathrm{M}_{2 / 3}$ & 0.66 & 0.62 & 0.54 & 0.78 & 0.60 & 0.58 & 0.64 & 0.53 & 0.61 & 9 \\
\hline & $\mathrm{F}_{2 / 3} \mathrm{M}_{1 / 3}$ & 0.58 & 0.64 & 0.58 & 0.72 & 0.65 & 0.74 & 0.75 & 0.57 & 0.66 & 6 \\
\hline & $\mathrm{F}_{1 / 3} \mathrm{M}_{2 / 3}$ & 0.54 & 0.92 & 0.95 & 0.75 & 0.73 & 0.51 & 0.75 & 0.43 & 0.71 & 3 \\
\hline & $\mathrm{F}_{1 / 3} \mathrm{M}_{1 / 3}$ & 0.54 & 0.97 & 0.97 & 0.99 & 0.96 & 0.50 & 0.76 & 0.33 & 0.76 & 2 \\
\hline & $\mathrm{CK}$ & 0.85 & 0.51 & 0.60 & 0.52 & 0.41 & 0.78 & 0.61 & 0.99 & 0.65 & 7 \\
\hline & $w_{j}$ & 0.07 & 0.11 & 0.15 & 0.10 & 0.15 & 0.16 & 0.14 & 0.12 & & \\
\hline
\end{tabular}

$\xi_{i 1}-\xi_{i 8}$ are grey relational coefficient of organic acid content, total soluble solids, total soluble sugar concentration, sugar-to-acid content ratio, fruit shape index, vitamin $\mathrm{C}$ content, lycopene content, and weight per fruit under different treatments respectively; $Q_{R i} *$ is the comprehensive fruit quality index given by grey relational analysis. See Table 1 for treatment descriptions. 
ranked $\mathrm{F}_{2 / 3} \mathrm{M}_{1}, \mathrm{~F}_{1 / 3} \mathrm{M}_{1}$, and $\mathrm{F}_{2 / 3} \mathrm{M}_{1 / 3}$ first, second, and third and $\mathrm{F}_{1 / 3} \mathrm{M}_{2 / 3}, \mathrm{~F}_{1} \mathrm{M}_{2 / 3}$, and $\mathrm{F}_{1} \mathrm{M}_{1 / 3}$ had lower values in 2017. In 2018, $\mathrm{F}_{2 / 3} \mathrm{M}_{1}, \mathrm{~F}_{2 / 3} \mathrm{M}_{1 / 3}$, and $\mathrm{F}_{1} \mathrm{M}_{2 / 3}$ ranked first, second, and third, and $\mathrm{F}_{1 / 3} \mathrm{M}_{1 / 3}, \mathrm{~F}_{2 / 3} \mathrm{M}_{2 / 3}$, and $\mathrm{F}_{1} \mathrm{M}_{1 / 3}$ had lower values (Table 4). PCA gave similar results to GRA, with $F_{1 / 3} M_{1 / 3}$ and $F_{2 / 3}$ $\mathrm{M}_{1}$ having higher comprehensive quality index values, and $F_{1} M_{2 / 3}, F_{1} M_{1 / 3}$, and $C K$ having lower values (Table 5). To assess how well the comprehensive quality index represents overall fruit quality, Spearman's rank correlation analysis between the comprehensive quality indexes computed by the different methods and the individual fruit quality parameters was conducted, and the rankings of the comprehensive quality indexes should be, as closely as possible, consistent with those of the individual quality parameters (Wang et al., 2011). The comprehensive quality indexes given by $\operatorname{GRA}\left(Q_{R i}{ }^{*}\right)$ and PCA $\left(Q_{P i}{ }^{*}\right)$ showed significant positive correlations with SI, TSS, SAR, and VC and significant negative correlation with OA. The comprehensive quality index given by TOPSIS $\left(Q_{T i}{ }^{*}\right)$ was significantly correlated with VC (Table 6). The results indicate that the ranking of the comprehensive quality indexes given by GRA and PCA better fitted the ranking of individual quality parameters. The Spearman correlation coefficients for TOPSIS and PCA $(0.77)$ and TOPSIS and GRA (0.83) were lower than for GRA or PCA alone. Thus, GRA and

Table 4. The normalize fruit quality parameters $\left(p_{i j}\right)$, comprehensive fruit quality indexes and its rankings for deficit irrigation at different growth stages using TOPSIS in 2017 and 2018.

\begin{tabular}{|c|c|c|c|c|c|c|c|c|c|c|c|c|c|}
\hline Crop season & Treatment & $p_{i 1}$ & $p_{i 2}$ & $p_{i 3}$ & $p_{i 4}$ & $p_{i 5}$ & $p_{i 6}$ & $p_{i 7}$ & $p_{i 8}$ & $\mathrm{~L}_{\mathrm{i}}^{+}$ & $\mathrm{L}_{\mathrm{i}}^{-}$ & $\mathrm{Q}_{\mathrm{Ti}}{ }^{*}$ & Rank \\
\hline \multirow[t]{11}{*}{2017} & $\mathrm{~F}_{1 / 3} \mathrm{M}_{1}$ & 0.11 & 0.11 & 0.12 & 0.11 & 0.11 & 0.11 & 0.12 & 0.16 & 0.02 & 0.04 & 0.74 & 2 \\
\hline & $\mathrm{F}_{2 / 3} \mathrm{M}_{1}$ & 0.09 & 0.12 & 0.13 & 0.11 & 0.14 & 0.12 & 0.12 & 0.17 & 0.00 & 0.06 & 0.95 & 1 \\
\hline & $\mathrm{F}_{1} \mathrm{M}_{2 / 3}$ & 0.14 & 0.10 & 0.08 & 0.11 & 0.08 & 0.12 & 0.10 & 0.12 & 0.04 & 0.02 & 0.35 & 8 \\
\hline & $\mathrm{F}_{1} \mathrm{M}_{1 / 3}$ & 0.14 & 0.10 & 0.09 & 0.11 & 0.08 & 0.11 & 0.10 & 0.08 & 0.05 & 0.01 & 0.20 & 9 \\
\hline & $\mathrm{F}_{2 / 3} \mathrm{M}_{2 / 3}$ & 0.09 & 0.12 & 0.12 & 0.11 & 0.14 & 0.12 & 0.11 & 0.08 & 0.03 & 0.04 & 0.57 & 4 \\
\hline & $\mathrm{F}_{2 / 3} \mathrm{M}_{1 / 3}$ & 0.10 & 0.12 & 0.13 & 0.11 & 0.13 & 0.11 & 0.11 & 0.10 & 0.03 & 0.04 & 0.62 & 3 \\
\hline & $\mathrm{F}_{1 / 3} \mathrm{M}_{2 / 3}$ & 0.09 & 0.12 & 0.10 & 0.11 & 0.13 & 0.11 & 0.11 & 0.07 & 0.04 & 0.03 & 0.49 & 7 \\
\hline & $\mathrm{F}_{1 / 3} \mathrm{M}_{1 / 3}$ & 0.09 & 0.12 & 0.13 & 0.11 & 0.14 & 0.10 & 0.12 & 0.05 & 0.04 & 0.04 & 0.51 & 5 \\
\hline & $\mathrm{CK}$ & 0.14 & 0.09 & 0.09 & 0.11 & 0.06 & 0.12 & 0.10 & 0.17 & 0.04 & 0.04 & 0.50 & 6 \\
\hline & $\mathrm{A}^{+}$ & 0.09 & 0.12 & 0.13 & 0.11 & 0.14 & 0.12 & 0.12 & 0.17 & & & & \\
\hline & $\mathrm{A}^{-}$ & 0.14 & 0.10 & 0.08 & 0.11 & 0.08 & 0.11 & 0.10 & 0.07 & & & & \\
\hline \multirow[t]{11}{*}{2018} & $\mathrm{~F}_{1 / 3} \mathrm{M}_{1}$ & 0.12 & 0.12 & 0.12 & 0.11 & 0.11 & 0.09 & 0.11 & 0.12 & 0.03 & 0.03 & 0.54 & 4 \\
\hline & $\mathrm{F}_{2 / 3} \mathrm{M}_{1}$ & 0.10 & 0.13 & 0.13 & 0.13 & 0.13 & 0.14 & 0.10 & 0.15 & 0.01 & 0.05 & 0.87 & 1 \\
\hline & $\mathrm{F}_{1} \mathrm{M}_{2 / 3}$ & 0.12 & 0.10 & 0.11 & 0.10 & 0.09 & 0.12 & 0.11 & 0.14 & 0.03 & 0.03 & 0.54 & 3 \\
\hline & $\mathrm{F}_{1} \mathrm{M}_{1 / 3}$ & 0.12 & 0.10 & 0.11 & 0.11 & 0.10 & 0.12 & 0.12 & 0.10 & 0.03 & 0.02 & 0.44 & 9 \\
\hline & $\mathrm{F}_{2 / 3} \mathrm{M}_{2 / 3}$ & 0.11 & 0.10 & 0.09 & 0.12 & 0.11 & 0.10 & 0.11 & 0.11 & 0.03 & 0.03 & 0.48 & 8 \\
\hline & $\mathrm{F}_{2 / 3} \mathrm{M}_{1 / 3}$ & 0.10 & 0.11 & 0.10 & 0.11 & 0.12 & 0.12 & 0.12 & 0.11 & 0.02 & 0.03 & 0.59 & 2 \\
\hline & $\mathrm{F}_{1 / 3} \mathrm{M}_{2 / 3}$ & 0.10 & 0.13 & 0.13 & 0.11 & 0.13 & 0.09 & 0.12 & 0.08 & 0.03 & 0.03 & 0.53 & 5 \\
\hline & $\mathrm{F}_{1 / 3} \mathrm{M}_{1 / 3}$ & 0.10 & 0.13 & 0.13 & 0.13 & 0.14 & 0.09 & 0.12 & 0.05 & 0.04 & 0.04 & 0.48 & 7 \\
\hline & CK & 0.13 & 0.09 & 0.10 & 0.09 & 0.07 & 0.12 & 0.10 & 0.15 & 0.04 & 0.04 & 0.51 & 6 \\
\hline & $\mathrm{A}^{+}$ & 0.10 & 0.13 & 0.13 & 0.13 & 0.14 & 0.14 & 0.12 & 0.15 & & & 0.74 & 2 \\
\hline & $\mathrm{A}^{-}$ & 0.13 & 0.09 & 0.09 & 0.09 & 0.07 & 0.09 & 0.10 & 0.05 & & & & \\
\hline
\end{tabular}

$p_{i 1}-p_{i 8}$ are the normalize fruit quality parameters of organic acid content, total soluble solids, total soluble sugar concentration, sugar-to-acid content ratio, fruit shape index, vitamin C content, lycopene content, and weight per fruit under different treatments respectively; $A^{+}\left(A^{-}\right)$are the best (worst) ideal solutions; $\mathrm{L}_{\mathrm{i}}^{+}\left(\mathrm{L}_{\mathrm{i}}^{-}\right)$ are the weighted Euclidean distance between $A_{i}$ and $A^{+}\left(A^{-}\right)$; $Q_{T i} *$ is the comprehensive fruit quality index given by the technique for order preference by similarity to an ideal solution. See Table 1 for treatment descriptions.

Table 5. The principal component, comprehensive fruit quality indexes, and its rankings for deficit irrigation at different growth stages using principal components analysis in 2017 and 2018.

\begin{tabular}{|c|c|c|c|c|c|c|c|}
\hline \multirow[b]{2}{*}{ Crop season } & \multirow[b]{2}{*}{ Treatments } & \multicolumn{2}{|c|}{ Principal component } & \multirow[b]{2}{*}{$\mathrm{d}_{\mathrm{i}}^{+}$} & \multirow[b]{2}{*}{$\mathrm{d}_{\mathrm{i}}^{-}$} & \multirow[b]{2}{*}{$\mathrm{Q}_{\mathrm{Pi}}^{*}$} & \multirow[b]{2}{*}{ Rank } \\
\hline & & $f_{1}$ & $f_{2}$ & & & & \\
\hline \multirow[t]{12}{*}{$\frac{1}{2017}$} & $\mathrm{~F}_{1 / 3} \mathrm{M}_{1}$ & 1.28 & 1.68 & 3.57 & 7.14 & 0.67 & 6 \\
\hline & $\mathrm{F}_{2 / 3} \mathrm{M}_{1}$ & 3.30 & 2.23 & 2.00 & 8.71 & 0.81 & 2 \\
\hline & $\mathrm{F}_{1} \mathrm{M}_{2 / 3}$ & -7.47 & -0.28 & 10.39 & 1.14 & 0.10 & 8 \\
\hline & $\mathrm{F}_{1} \mathrm{M}_{1 / 3}$ & -3.19 & -2.74 & 7.38 & 3.39 & 0.31 & 7 \\
\hline & $\mathrm{F}_{2 / 3} \mathrm{M}_{2 / 3}$ & 1.51 & 0.95 & 3.44 & 7.22 & 0.68 & 5 \\
\hline & $\mathrm{F}_{2 / 3} \mathrm{M}_{1 / 3}$ & 3.62 & -0.11 & 2.06 & 8.73 & 0.81 & 3 \\
\hline & $\mathrm{F}_{1 / 3} \mathrm{M}_{2 / 3}$ & 2.63 & -1.51 & 3.05 & 7.91 & 0.72 & 4 \\
\hline & $\mathrm{F}_{1 / 3} \mathrm{M}_{1 / 3}$ & 5.89 & -1.11 & 1.55 & 10.43 & 0.87 & 1 \\
\hline & $\mathrm{CK}$ & -7.57 & 0.89 & 10.42 & 1.68 & 0.14 & 9 \\
\hline & Weight & 0.60 & 0.21 & & & & \\
\hline & $\mathrm{f}_{\mathrm{j}}^{+}$ & 5.89 & 2.23 & & & & \\
\hline & $\mathrm{f}_{\mathrm{j}}^{-}$ & -7.57 & -2.74 & & & & \\
\hline \multirow[t]{12}{*}{2018} & $\mathrm{~F}_{1 / 3} \mathrm{M}_{1}$ & 0.91 & -0.21 & 6.25 & 7.63 & 0.55 & 4 \\
\hline & $\mathrm{F}_{2 / 3} \mathrm{M}_{1}$ & 2.04 & 3.77 & 5.10 & 8.83 & 0.63 & 3 \\
\hline & $\mathrm{F}_{1} \mathrm{M}_{2 / 3}$ & -5.08 & 0.19 & 10.91 & 2.92 & 0.21 & 8 \\
\hline & $\mathrm{F}_{1} \mathrm{M}_{1 / 3}$ & -2.15 & -1.64 & 8.78 & 5.16 & 0.37 & 7 \\
\hline & $\mathrm{F}_{2 / 3} \mathrm{M}_{2 / 3}$ & -1.19 & -0.37 & 7.89 & 5.95 & 0.43 & 6 \\
\hline & $\mathrm{F}_{2 / 3} \mathrm{M}_{1 / 3}$ & 0.09 & -0.56 & 6.92 & 6.96 & 0.50 & 5 \\
\hline & $\mathrm{F}_{1 / 3} \mathrm{M}_{2 / 3}$ & 5.53 & -0.53 & 2.98 & 11.31 & 0.79 & 2 \\
\hline & $\mathrm{F}_{1 / 3} \mathrm{M}_{1 / 3}$ & 8.42 & -0.77 & 1.98 & 13.61 & 0.87 & 1 \\
\hline & $\mathrm{CK}$ & -8.59 & 0.12 & 13.70 & 0.77 & 0.05 & 9 \\
\hline & Weight & 0.64 & 0.19 & & & & \\
\hline & $\mathrm{f}_{\mathrm{j}}^{+}$ & 8.42 & 3.77 & & & & \\
\hline & $\mathrm{f}_{\mathrm{j}}^{-}$ & -8.59 & -1.64 & & & & \\
\hline
\end{tabular}

$f_{j}$ is the principal component column, $f_{j}^{+}\left(f_{j}^{-}\right)$are the maximum (minimum) value among the $f_{j}, d_{j}^{+}\left(d_{j}^{-}\right)$are the maximum (minimum) value of principal component; $\mathrm{Q}_{\mathrm{Pi}}{ }^{*}$ is the comprehensive fruit quality index given by principal components analysis. See Table 1 for treatment descriptions. 
Table 6. Spearman rank correlation coefficients between comprehensive fruit quality indexes given by different analyses and individual fruit quality parameters in 2017 and 2018.

\begin{tabular}{lcclccccc}
\hline Analysis & Wt per fruit & SI & OA & TSS & TSSC & SAR & VC \\
\hline TOPSIS & 0.47 & 0.29 & -0.14 & 0.45 & 0.03 & 0.20 & $0.65^{*}$ & 0.12 \\
GRA & -0.01 & $0.54^{* *}$ & $-0.53^{* *}$ & $0.69^{* *}$ & 0.32 & $0.61^{*}$ & $0.88^{* *}$ & 0.15 \\
PCA & -0.27 & $0.63^{* *}$ & $-0.76^{*}$ & $0.66^{* *}$ & 0.45 & $0.80^{* *}$ & $0.72^{* *}$ & 0.20 \\
\hline
\end{tabular}

GRA = grey relational analysis; $\mathrm{LYC}=$ lycopene content; $\mathrm{OA}=$ organic acid content; $\mathrm{PCA}=$ principal components analysis; $\mathrm{SAR}=$ sugar-to-acid content ratio; SI $=$ fruit shape index; TOPSIS $=$ technique for order preference by similarity to an ideal solution; TSS $=$ total soluble solids; TSSC $=$ total soluble sugar concentration; $\mathrm{VC}=$ vitamin $\mathrm{C}$ content.

*The correlation is significant at the 0.05 level; **correlation is significant at the 0.01 level.

Table 7. The comprehensive fruit quality and its ranks for deficit irrigation at different growth stage calculated by combinatorial evaluation method by grey relational analysis and principal components analysis in 2017 and 2018.

\begin{tabular}{|c|c|c|c|c|c|c|c|c|c|c|}
\hline \multirow{2}{*}{$\begin{array}{l}\text { Crop seasons } \\
2017\end{array}$} & Items & $\mathrm{F}_{1 / 3} \mathrm{M}_{1}$ & $\mathrm{~F}_{2 / 3} \mathrm{M}_{1}$ & $\mathrm{~F}_{1} \mathrm{M}_{2 / 3}$ & $\mathrm{~F}_{1} \mathrm{M}_{1 / 3}$ & $\mathrm{~F}_{2 / 3} \mathrm{M}_{2 / 3}$ & $\mathrm{~F}_{2 / 3} \mathrm{M}_{1 / 3}$ & $\mathrm{~F}_{1 / 3} \mathrm{M}_{2 / 3}$ & $\mathrm{~F}_{1 / 3} \mathrm{M}_{1 / 3}$ & CK \\
\hline & Rank & 5 & 1 & 8 & 7 & 4 & 3 & 6 & 2 & 9 \\
\hline \multirow[t]{2}{*}{2018} & $\mathrm{Q}_{\mathrm{ci}}{ }^{*}$ & 0.60 & 0.75 & 0.43 & 0.50 & 0.52 & 0.58 & 0.75 & 0.82 & 0.34 \\
\hline & Rank & 4 & 2 & 8 & 7 & 6 & 5 & 3 & 1 & 9 \\
\hline
\end{tabular}

$\mathrm{Q}_{\mathrm{ci}}^{*}$ is the comprehensive fruit quality index given by combinatorial evaluation method by grey relational analysis and principal components analysis. See Table 1 for treatment descriptions.

PCA create more suitable indicators than TOPSIS for calculating the comprehensive quality index. Wang et al. (2015) also found that GRA and PCA gave similar results in calculating the comprehensive quality index for tomatoes under different water deficit programs. Thus we combined GRA with PCA to calculate the combined comprehensive quality index of tomatoes.

In the combined comprehensive quality indexes (Table 7), $F_{2 / 3} M_{1}$ and $F_{1 / 3} M_{1 / 3}$ had higher comprehensive quality index values, and CK ranked last. This was mainly because these treatments led to higher TSS, TSSC, SAR, and lycopene contents, and the comprehensive quality index was determined from the observed values of the individual quality parameters. $F_{1 / 3} \mathrm{M}_{1 / 3}$ had a low yield, whereas $\mathrm{F}_{2 / 3} \mathrm{M}_{1}$ had high fruit quality and yield was not significantly reduced. This result shows that a balance between improved fruit quality and acceptable yield may be achieved under a moderate water deficit at the flowering and fruit development stage.

The relationships between the comprehensive quality indexes and $1-\mathrm{ET}_{\mathrm{i}} / \mathrm{ET}_{\mathrm{c}}$ were analyzed (Fig. 3). The comprehensive quality indexes given by GRA, PCA, and combined GRA and PCA showed positive linear correlations with $1-\mathrm{ET}_{\mathrm{i}} / \mathrm{ET}_{\mathrm{c}}$, with $R^{2}$ of $0.39-0.91$. These results are consistent with the relationships between the individual fruit quality parameters and $1-\mathrm{ET}_{\mathrm{i}} / \mathrm{ET}_{\mathrm{c}}$. The equation relating the comprehensive quality index and ET provides a basic model to guide highquality tomato production.

\section{Conclusions}

The results of this study show that deficit irrigation significantly decreased ET and improved fruit quality. Deficit irrigation resulted in significant increases in TSS, TSSC, SAR, and VC and decreases in OA and lycopene compared with full irrigation. Fruit quality was more sensitive to water deficit at the flowering and fruit development stage than at fruit maturation. The yield was significantly reduced when the water deficit
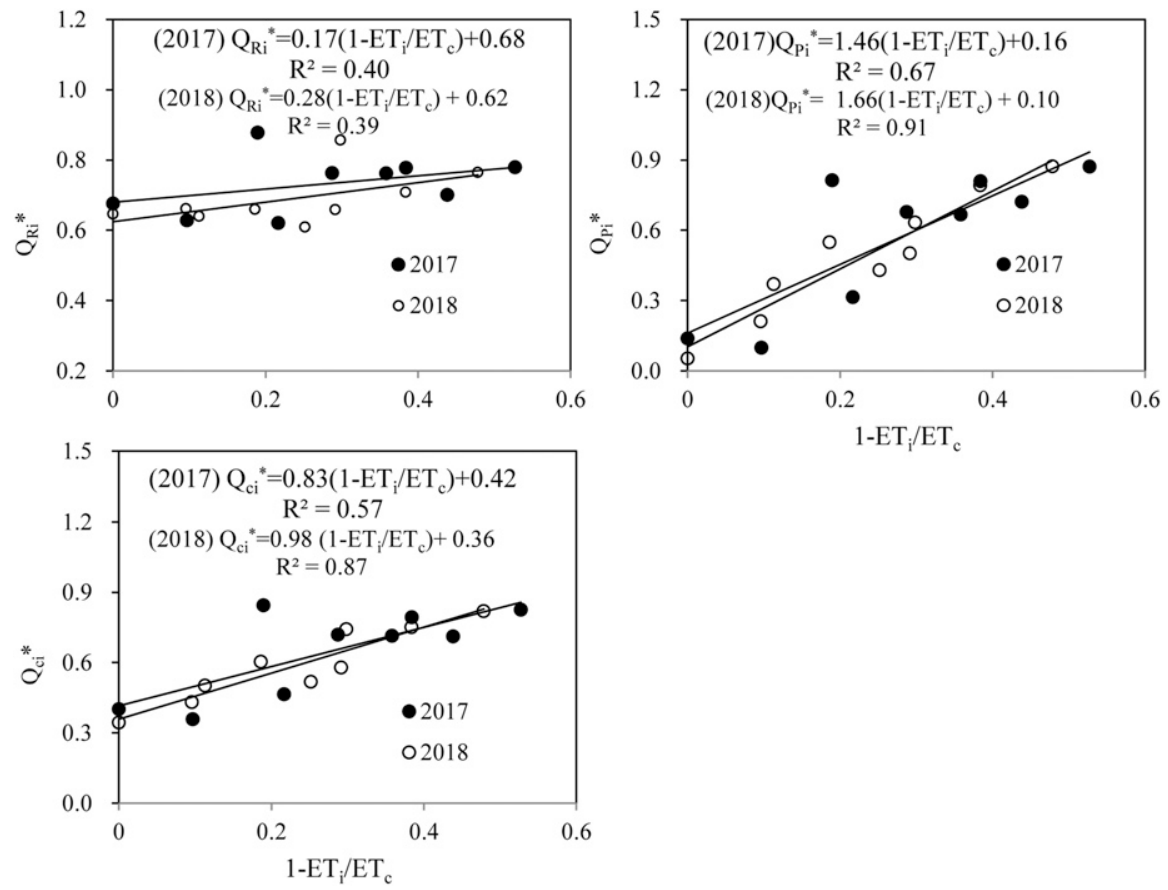

Fig. 3. Relationships between comprehensive fruit quality index with grey relational analysis (GRA; $Q_{\mathrm{ri}}{ }^{*}$ ), principal components analysis (PCA; $\left.Q_{\mathrm{Pi}}^{*}\right)$, and combined GRA and PCA $\left(Q_{c i}^{*}\right)$ and relative seasonal water deficit $\left(1-\mathrm{ET}_{\mathrm{i}} / \mathrm{ET}_{\mathrm{c}}\right)$ in 2017 and 2018.

increased in both years, except for treatment $\mathrm{F}_{2 / 3} \mathrm{M}_{1}$ (two-thirds full irrigation at flowering and fruit development stage). Relative yield and relative OA showed significant negative linear correlations with relative seasonal water deficit. Other relative individual fruit quality parameters showed significant positive linear correlations with relative seasonal water deficit. SAR, OA, and TSS in particular were influenced by water deficit. The comprehensive quality indexes given by GRA combined with PCA are reliable indicators because the comprehensive quality index rankings were consistent with those of most individual fruit quality parameters. The comprehensive quality indexes produced by GRA, PCA, and the combination of GRA and PCA showed positive linear correlation with relative seasonal water deficit. The comprehensive quality ranking for the combination of GRA and PCA showed that $\mathrm{F}_{2 / 3}$ $\mathrm{M}_{1}$ produced higher fruit quality without a significant yield decrease compared with other treatments, which indicated that a balance between improved fruit quality and acceptable yield can be achieved under an appropriate water deficit level at the flowering and fruit development stage.

\section{Literature Cited}

Al-Amri, S.M. 2013. Improved growth, productivity and quality of tomato (Solanumly copersicum L.) plants through application of shikimic acid. Saudi J. Biol. Sci. 20:339-345. 
Association of Official Analytical Chemists. 1984. Vitamin C (ascorbic acid) in vitamin preparations and juices: 2,6-dichloroindophenol titrimetric method, p. 844-845. Association of Official Analytical Chemists, Washington, DC.

Association of Official Analytical Chemists. 1990. Official methods of analysis. 15th ed. Association of Official Analytical Chemists, Washington, DC.

Chamodrakas, I., N. Alexopoulou, and D. Martakos. 2009. Customer evaluation for order acceptance using a novel class of fuzzy methods based on TOPSIS. Expert Syst. Appl. 36:7409-7415.

Chen, J., S. Kang, T. Du, R. Qiu, P. Guo, and R. Chen. 2013. Quantitative response of greenhouse tomato yield and quality to water deficit at different growth stages. Agr. Water Mgt. 129(11):152-162.

Chen, J., S. Kang, T. Du, P. Guo, R. Qiu, R. Chen, and F. Gu. 2014. Modeling relations of tomato yield and fruit quality with water deficit at different growth stages under greenhouse condition. Agr. Water Mgt. 146:131-148.

Davies, B.H. 1976. Carotenoids, p. 38-165. In: T.W. Goodwin (ed.). Chemistry and biochemistry of plant pigments. Academic Press, London.

Deng, H., C.H. Yeh, and R.J. Willis. 2000. Intercompany comparison using modified TOPSIS with objective weights. Comput. Oper. Res. 27:963-973.

Dorais, M., A. Papadopoulos, and A. Gosselin. 2001. Greenhouse tomato fruit quality. Hort. Rev. 26:239-319.

Dumas, Y., M. Dadomo, G. Di Lucca, and P. Grolier. 2003. Effects of environmental factors and agricultural techniques on antioxidant content of tomatoes. J. Sci. Food Agr. 83:369-382.

Erba, D., M.C. Casiraghi, A. Ribas-Agustí, R. Cáceres, O. Marfâ, and M. Castellari. 2013. Nutritional value of tomatoes (Solanum lycopersicum L.) grown in greenhouse by different agronomic techniques. J. Food Compos. Anal. $31: 245-251$.

Favati, F., S. Lovelli, F. Galgano, V. Miccolis, T. Di Tommaso, and V. Candido. 2009. Processing tomato quality as affected by irrigation scheduling. Scientia Hort. 122:562-571.

Fung, C.P. and P.C. Kang. 2005. Multi-response optimization in friction properties of PBT composites using Taguchi method and principle component analysis. J. Mater. Process. Technol. 170:602-610.

Hanson, B.R., R.B. Hutmacher, and D.M. May. 2006. Drip Irrigation of Tomato and Cotton Under Shallow Saline Ground Water Conditions. Irrig. Drain. Syst. 20(2-3):155-175.

Jensen, C.R., A. Battilani, F. Plauborg, G. Psarras, K. Chartzoulakis, F. Janowiak, R. Sti-kic, Z. Jovanovic, G.T. Li, X.B. Qi, F.L. Liu, S.E. Jacobsen, and M.N. Andersen. 2010. Deficit irrigation based on drought tolerance and root signaling in potatoes and tomatoes. Agr. Water Mgt. 98:403-413.

Jing, K. and Z.Z. Hong. 2012. Time prediction model for pipeline leakage based on grey relational analysis. Phys. Proc. 25:2019-2024.

Kader, A.A. 2008. Flavor quality of fruits and vegetables. J. Sci. Food Agr. 88:1863-1868.

Karam, F., R. Lahoud, R. Masaad, R. Kabalan, J. Breidi, C. Chalita, and Y. Rouphael. 2007. Evapotranspiration, seed yield and water use efficiency of drip irrigated sunflower under full and deficit irrigation conditions. Agr. Water Mgt. 90:213-223.
Kuscu, H., A. Turhan, and A.O. Demir. 2014. The response of processing tomato to deficit irrigation at various phonological stages in a sub-humid environment. Agr. Water Mgt. 133:92-103.

Lan, C.H., Y.L. Huang, S.H. Ho, and C.Y. Peng. 2014. Volatile organic compound identification and characterization by PCA and mapping at a high-technology science park. Environ. Pollut. 193:156-164.

Leyva, A., A. Quintana, M. Sánchez, E.N Rodríguez, J. Cremata, and J.C. Sánchez. 2008. Rapid and sensitive anthrone-sulfuric acid assay in microplate format to quantify carbohydrate in biopharmaceutical products: Method development and validation. Biologicals 36(2):134-141.

Lu, H.S., C.K. Chang, N.C. Hwang, and C.T Chung. 2009. Grey relational analysis coupled with principal component analysis for optimization design of the cut-ting parameters in high-speed end milling. J. Mater. Process. Technol. 209:3808-3817.

Marouelli, W.A. and W.L.C. Silva. 2007. Water tension thresholds for processing tomatoes under drip irrigation in Central Brazil. Irrig. Sci. 25:411-418.

Massot, C., M. Génard, R. Stevens, and H. Gautier. 2010. Fluctuations in sugar content are determinant in explaining variations in vitamin $\mathrm{C}$ in tomato fruit. Plant Physiol. Biochem. 48:751-757.

Mitchell, J.P., C. Shennan, S.R. Grattan, and D.M. May. 1991. Tomato fruit yield and quality under water deficit and salinity. J. Amer. Soc. Hort. Sci. 116:215-221.

Nguyen, M.L. and S.J. Schwartz. 1999. Lycopene: Chemical and biological properties. Food Technol. 53:38-45.

Qiu, R., Y. Jing, C. Liu, Z. Yang, and Z.C. Wang. 2017a. Response of hot pepper yield, fruit quality and fruit ion content to irrigation water salinity and leaching fractions. HortScience 52:979-985.

Qiu, R.J., C.W. Liu, Z.C. Wang, Z.Q. Yang, and Y.S. Jing. 2017b. Effects of irrigation water salinity on evapotranspiration modified by leaching fractions in hot pepper plants. Sci. Rep. 7:7231.

Qiu, R., Z. Yang, Y. Jing, C. Liu, X. Luo, and Z. Wang. 2018. Effects of irrigation water salinity on the growth, gas exchange parameters, and ion concentration of hot pepper plants modified by leaching fractions. HortScience 53:10501055.

Patanè, C. and S.L. Cosentino. 2010. Effects of soil water deficit on yield and quality of processing tomato under a Mediterranean climate. Agr. Water Mgt. 97:131-138.

Patanè, C., S. Tringali, and O. Sortino. 2011. Effect of deficit irrigation on biomass, yield, water use efficiency an fruit quality of processing tomato under semi-arid Mediterranen climate conditions. Scientia Hort. 129(4):590-596.

Sezen, S.M., A. Yazar, A. Asiye, H.Y. Dasgan, and B. Gencel. 2008. Yield and quality response of drip irrigated green beans under full and deficit irrigation. Scientia Hort. 117:95-102.

Sharma, S. and M. Le Maguer. 1996. Lycopene in tomatoes and tomato pulp fractions. Ital. J. Food Sci. 8(2):107-113.

Stewart, J.I., R.H. Cuenca, W.O. Pruit, R.M. Hagan, and J. Tosso. 1977. Determination and Utilization of Water Production Functions for Principal California Crops. W-67 California
Contribution Project Report. University of California, Davis, CA.

Sun, Y., K.L. Hu, Z.B. Fan, Y.P. Wei, S. Lin, and J.G. Wang. 2013. Simulating the fate of nitrogen and optimizing water and nitrogen management of greenhouse tomato in North China using the EU-Rotate N model. Agr. Water Mgt. 128:72-84.

Tamrin, K.F., Y. Nukman, N.A. Sheikh, and M.Z. Harizam. 2014. Determination of optimum parameters using grey relational analysis for multi-performance characteristics in $\mathrm{CO}_{2}$ laser joining of dissimilar materials. Opt. Lasers Eng. 57:40-47.

Toor, R.K., G.P. Savage, and A. Heeb. 2006. Influence of different types of fertilizers on the major antioxidant components of tomatoes. J. Food Compos. Anal. 19:20-27.

Topcu, S., C. Kirda, Y. Dasgan, H. Kaman, M. Cetin, A. Yazici, and M.A. Bacon. 2007. Yield response and $\mathrm{N}$-fertiliser recovery of tomato grown under deficit irrigation. Eur. J. Agron. 26:64-70.

Veit-Köhler, U., A. Krumbein, and H. Kosegarten. 1999. Effect of different water supply on plant growth and fruit quality of Lycopersicon esculentum. J. Soil Sci. Plant Nutr. 162:583-588.

Wang, C., F. Gu, J. Chen, H. Yang, J. Jiang, T. Du, and J. Zhang. 2015. Assessing the response of yield and comprehensive fruit quality of tomato grown in greenhouse to deficit irrigation and nitrogen application strategies. Agr. Water Mgt. 161(5):9-19.

Wang, F., S. Kang, T. Du, F. Li, and R. Qiu. 2011. Determination of comprehensive quality index for tomato and its response to different irrigation treatments. Agr. Water Mgt. 98(8):12281238

Wang, J., K. Fan, and W. Wang. 2010. Integration of fuzzy AHP and FPP with TOPSIS methodology for aeroengine health assessment. Expert Syst. Appl. 37:8516-8526.

Wang, S., X.M. Jiang, Q. Wang, X.X. Han, and H.S. Ji. 2013. Experiment and grey relational analysis of seaweed particle combustion in a fluidized bed. Energy Convers. Manage. 66:115-120.

Xiao, X.C., X.Q. Wang, K.Y. Fu, and Y.J. Zhao. 2012. Grey relational analysis on factors of the quality of web service. Phys. Proc. 33:19921998.

Xie, Y. and Z. Mao. 2012. Evaluation of residential energy-saving buildings based on grey relational analysis method. Proc. Eng. 29:31493153.

Yang, H., T. Du, R. Qiu, J. Chen, F. Wang, Y. Li, C. Wang, L. Gao, and S. Kang. 2017. Improved water use efficiency and fruit quality of greenhouse crops under regulated deficit irrigation in northwest china. Agr. Water Mgt. 179:193204.

Zabalza, J., J.C. Ren, M.Q. Yang, Y. Zhang, J. Wang, S. Marshall, and J.W. Han. 2014. NovelFolded-PCA for improved feature extraction and data reduction with hyper-spectral imaging and SAR in remote sensing. ISPRS J. Photogramm. Remote Sens. 93:112-122.

Zheng, J., G. Huang, D. Jia, J. Wang, M. Mota, L.S. Pereira, Q. Huang, X. Xu, and H. Liu. 2013. Responses of drip irrigated tomato (Solanum lycopersicum $L$.) yield, quality and water use efficiency to various soil matric potential thresholds in an arid region of Northwest China. Agr. Water Mgt. 129:181-193. 